\title{
First year of life after the use of atenolol in pregnancy associated hypertension
}

\author{
B REYNOLDS, L BUTTERS, J EVANS, T ADAMS, AND P C RUBIN
}

University Department of Materia Medica and Divisions of Paediatrics and Obstetrics and Gynaecology, Stobhill General Hospital, Glasgow

SUMmARY We describe the results of a prospective study in which 120 women who developed hypertension in the last trimester of pregnancy were randomly allocated in double blind manner to atenolol or placebo. The mean duration of treatment was five weeks. The only difference between groups during the neonatal period was in respiratory distress syndrome, mainly related to spontaneous premature labour, which occurred in six placebo group babies but in none from the atenolol group. Fifty'five children from each group have been followed to 1 year of age. All in the atenolol group are developing normally but one child from the placebo group is brain damaged. These findings do not suggest any short or medium term paediatric complications after the use of beta blockers in pregnancy.

Beta adrenoceptor antagonists have become widely accepted in general medical practice. Their introduction to obstetrics, however, has been accompanied by concern about a wide range of adverse effects largely affecting the fetus and neonate. These drugs have been implicated in the production of growth retardation of the fetus ${ }^{1}$ and have had ascribed to them a considerable range of neonatal problems including hypoglycaemia, hyperbilirubinaemia, bradycardia, respiratory depression, and death. ${ }^{2-8}$ The precise relation between these complications and drug administration was difficult to evaluate because of the anecdotal or retrospective nature of observations in patients who had major disorders of pregnancy. ${ }^{9}$ We have recently completed a placebo-controlled evaluation of the beta blocker atenolol in women with pregnancy associated hypertension ${ }^{10}$ and describe here the findings of paediatric follow up to 1 year of age.

\section{Methods}

One hundred and twenty women who developed a blood pressure of between $140 / 90$ and 170/110 mmHg on two occasions 24 hours apart during the last trimester of pregnancy were randomly allocated in double blind manner to treatment with atenolol or placebo. The maximum dose of atenolol was 200 mg per day and the average duration of treatment was five weeks. No other antihypertensive medication was prescribed. All babies were admitted to the special care nursery where they had a detailed clinical examination including measurement of weight, length, occipitofrontal circumference, triceps and subscapular skinfold thickness, together with assessment of gestation by the Dubowitz method. ${ }^{11}$ The results of biochemical, haemodynamic, and pharmacokinetic measurements made during this period have previously been reported. ${ }^{10} 12$ Infants were subsequently seen at 3,8 , and 12 months of age when a Denver development screening test was performed and growth indices were recorded. At all stages of assessment the investigator performing the evaluation was unaware of treatment category.

Data are presented as mean (standard deviation) and analysis is by intention to treat. Continuous variables recorded in the neonatal assessment were compared by unpaired two sided $t$ test and in the subsequent paediatric follow up by repeated measures analysis of variance. Categorical variables were compared by analysis of contingency $\left(\chi^{2}\right)$.

\section{Results}

There were no major congenital malformations in either group. Two babies from the placebo group had abnormalities on clinical examination at birth: one congenital dislocation of the hip and one patent ductus arteriosus. Four babies had abnormal examinations in the atenolol group: two had congenital dislocation of the hip and two minor glandular 
hypospadias. In all cases the abnormalities resolved without medical intervention. Clinical indices at birth are shown in Table 1.

Respiratory distress syndrome requiring ventilation occurred in six babies from the placebo group but in none from the atenolol group $(\mathrm{P}<0.05)$. The reasons for delivery in these six babies were spontaneous premature labour (4), caesarian section for fulminating pre-eclampsia (1), and caesarian section because of spontaneous premature labour and bad obstetric history (1).

Fifty five babies from each group attended for follow up examination through to 1 year of age. Clinical examination was normal by 12 months in all children who had defects identified at birth. Three children from the placebo group had less than a normal score on the Denver development screening test. Two were graded as 'doubtful' at 8 months but were classified 'normal' at both 3 and 12 months. One of these was born at term but was below the

Table 1 Clinical indices at birth (values mean (SD))

\begin{tabular}{lll}
\hline & $\begin{array}{l}\text { Placebo } \\
\text { group }\end{array}$ & $\begin{array}{l}\text { Atenolol } \\
\text { group }\end{array}$ \\
\hline $\begin{array}{l}\text { Length (cm) } \\
\text { Occipitofrontal }\end{array}$ & $48.6(3 \cdot 0)$ & $48.6(2 \cdot 7)$ \\
$\quad$ circumference (cm) & $33.9(2 \cdot 0)$ & $33.8(1 \cdot 7)$ \\
Dubowitz: neurological & $27(3 \cdot 6)$ & $27.4(2 \cdot 7)$ \\
Dubowitz: morphological & $25 \cdot 1(4 \cdot 6)$ & $26.6(3.9)$ \\
Gestational age (weeks) & $38.5(2 \cdot 1)$ & $39.1(1.5)$ \\
Triceps thickness (mm) & $4 \cdot 3(1 \cdot 2)$ & $4 \cdot 1(1 \cdot 0)$ \\
Subscapular thickness (mm) & $4.5(1.4)$ & $4.4(1 \cdot 3)$ \\
\hline
\end{tabular}

Table 2 Clinical indices at 3, 8, and 12 months of age (values mean (SD))

\begin{tabular}{|c|c|c|}
\hline & $\begin{array}{l}\text { Placebo } \\
\text { group }\end{array}$ & $\begin{array}{l}\text { Atenolol } \\
\text { group }\end{array}$ \\
\hline \multicolumn{3}{|c|}{ Weight (kg) } \\
\hline 3 & $5.59(0.76)$ & $5.72(0.76)$ \\
\hline 8 & $8.07(0.89)$ & $8.37(0.86)$ \\
\hline 12 & $9.58(0.97)$ & $9.64(1.19)$ \\
\hline \multicolumn{3}{|c|}{ Length $(\mathrm{cm})$} \\
\hline 3 & $60 \cdot 2(3.0)$ & $59 \cdot 8(2 \cdot 6)$ \\
\hline 8 & $68.9(2.6)$ & $68 \cdot 7(2 \cdot 1)$ \\
\hline 12 & $72 \cdot 4(2 \cdot 4)$ & $72 \cdot 7(2 \cdot 3)$ \\
\hline \multicolumn{3}{|c|}{ Occipitofrontal circumference } \\
\hline 3 & $40 \cdot 8(1 \cdot 3)$ & $40 \cdot 5(1 \cdot 2)$ \\
\hline 8 & $45.0(1.4)$ & $44 \cdot 6(1 \cdot 2)$ \\
\hline 12 & $46 \cdot 8(1 \cdot 2)$ & $46 \cdot 6(1.4)$ \\
\hline \multicolumn{3}{|c|}{ Triceps thickness ( $\mathrm{mm}$ ) } \\
\hline 3 & $6.8(1.2)$ & $6.9(1 \cdot 2)$ \\
\hline 8 & $8.5(1.2)$ & $8.2(1.2)$ \\
\hline 12 & $8.5(1.3)$ & $8.6(1.2)$ \\
\hline \multicolumn{3}{|c|}{ Subscapular thickness (mm) } \\
\hline 3 & $6.7(1.2)$ & $6 \cdot 7(1 \cdot 2)$ \\
\hline 8 & $6.9(1.2)$ & $7 \cdot 1(1 \cdot 2)$ \\
\hline 12 & $7 \cdot 2(1 \cdot 3)$ & $7 \cdot 3(1 \cdot 2)$ \\
\hline
\end{tabular}

10th centile for weight and length and had bradycardia for the first 12 hours of life. The second was born at 39 weeks' gestation after induction of labour because of maternal hypertension, and showed signs of cerebral irritation for two days. The third child was definitely abnormal at all three follow up visits. She was born by caesarean section after spontaneous premature labour at 35 weeks, was below the fifth centile for weight, length, occipitofrontal circumference, and was slow to establish respiration, and was nursed in oxygen for 48 hours. Clinical evaluation at 12 months of age confirmed the presence of a spastic quadriparesis with a severe pseudo-bulbar palsy. All children in the atenolol group were graded as normal on Denver development screening test at all stages of follow up. The remaining clinical indices at 3,8 , and 12 months of age are shown in Table 2. There were no further differences between the groups.

\section{Discussion}

Maternal morbidity and mortality now represent rare complications of hypertensive pregnancy and therapeutic intervention is directed largely at the fetus. There has been increasing use of antihypertensive drugs in all forms of pregnancy hypertension during recent years. ${ }^{13}$ Among the various drugs used, methyldopa has been shown to be effective in lowering blood pressure ${ }^{14}$ and safe for the fetus ${ }^{15} 16$ but maternal side effects necessitated stopping treatment in $14.5 \%$ of women. ${ }^{14}$ Beta blockers have been shown to have similar efficacy to methyldopa in lowering blood pressure ${ }^{17}$ but have been held responsible for a wide range of fetal and neonatal adverse effects. ${ }^{9}$ Since beta blockers are used only in pregnancies having a major complication, usually severe hypertension, it can be very difficult to differentiate drug effects on the fetus from those caused by the disease. Such difficulties are overcome by a placebo controlled and double blind design as used in this study.

We have previously described the absence of adverse biochemical effects of atenolol in the neonatal period. ${ }^{10}$ The further data presented here provide no support for a harmful effect of beta blockers on the fetus or neonate, with both acute and long term clinical problems being concentrated in the placebo group. The largest single aetiological factor in morbidity was spontaneous premature labour, accounting directly or indirectly for five cases of severe respiratory distress syndrome and the one case of chronic disability. It seems unlikely that a beta-1 adrenoceptor antagonist such as atenolol would directly influence uterine motility, and the most reasonable inference to draw is that 
poor blood pressure control was responsible for the premature labour.

These findings relate to a consecutively recruited series of patients attending the obstetric unit of a district general hospital. They serve to emphasise the importance of good blood pressure control in relation to pregnancy outcome. These data, however, do not suggest that beta blockers used during the last trimester are likely to be associated with major fetal, neonatal or paediatric adverse effects.

This study was supported in part by grant from Imperial Chemical Industries PLC.

PCR is a Wellcome Trust Senior Fellow in Clinical Science.

\section{References}

${ }^{1}$ Pruyn WC, Phelen JP, Buchanan GC. Long term propranolol therapy in pregnancy: maternal and fetal outcome. Am J Obstet Gynecol 1979;135:485-9.

2 Reed RL, Cheney CB, Fearon RE, Hook R, Hehre FW. Propranolol therapy throughout pregnancy: a case report. Anesth Analg 1974;53:214-8.

${ }^{3}$ Fiddler GI. Propranolol and pregnancy. Lancet 1974;ii:722-3.

${ }^{4}$ Gladstone GR, Hordof A, Gersony WM. Propranolol administration during pregnancy: effects on the fetus. J Pediatr 1975;86:962-4.

5 Habib A, McCarthy JS. Effects on the neonate of propranolol administered during pregnancy. J Pediatr 1977;91:808-11.

6 Cottrill CM, McAllister RG, Gettes L, Noonan JA. Propranolol therapy during pregnancy, labor and delivery: evidence for transplacental drug transfer and impaired drug disposition. J Pediatr 1977;91:812-4
${ }^{7}$ Lieberman BA, Stirrat GM, Dohen SL, Beard RW, Pinker GD Belsey $\mathrm{E}$. The possible adverse effects of propranolol on the fetus in pregnancies complicated by severe hypertension. $\mathrm{Br} \mathrm{J}$ Obstet Gynaecol 1978;85:678-83.

${ }^{8}$ Woods DL, Morrell DF. Atenolol: side effects in a newborn infant. $B r$ Med $J$ 1982;285:691-2.

9 Rubin PC. Beta blockers in pregnancy. $N$ Engl $J$ Med 1981;305:1323-6.

${ }^{10}$ Rubin PC, Butters L, Clark D, et al. Placebo-controlled trial of atenolol in treatment of pregnancy associated hypertension. Lancet 1983;i:431-4.

11 Dubowitz LM, Dubowitz V, Goldberg C. Clinical assessment of gestational age in the newborn infant. $J$ Pediatr 1970;77:1-10.

12 Rubin PC, Butters L, Reynolds B, et al. Atenolol elimination in the neonate. Br J Clin Pharmacol 1983;16:659-62.

13 Rubin PC. Hypertension occurring during pregnancy. In: Robertson JIS, ed. Handbook of hypertension. Vol. 2. Amsterdam: Elsevier, 1983:304-18.

14 Redman CWG, Beilin LJ, Bonnar J. Treatment of hypertension in pregnancy with methyldopa: blood pressure control and side effects. Br J Obstet Gynaecol 1977;84:419-26.

15 Redman CWG, Beilin LJ, Bonnar J, Ounsted MK. Fetal outcome in trial of antihypertensive treatment in pregnancy. Lancet 1976;ii:753-6.

16 Cockburn J, Moar VA, Ounsted M, Redman CWG. Final report of study on hypertension during pregnancy: the effects of specific treatment on the growth and development of the children. Lancet 1982; $\mathbf{i} 647-9$.

${ }^{17}$ Fidler J, Smith V, Fayers P, De Swiet M. Randomised controlled comparative study of methyldopa and oxprenolol in treatment of hypertension in pregnancy. $\mathrm{Br}$ Med $J$ 1983;286:1927-30.

Correspondence to Dr P C Rubin, University Department of Materia Medica, Stobhill General Hospital, Glasgow, G21 3UW.

Received 9 August 1984 